\title{
Social Patterning in Grip Strength, Chair Rise, and Walk Speed in an Aging Population: The Czech HAPIEE Study
}

\author{
Jitka Jancova-Vseteckova, Martin Bobak, Ruzena Kubinova, Nada Capkova, \\ Anne Peasey, Michael G. Marmot, and Hynek Pikhart
}

\begin{abstract}
Background: The aim was to examine the association of objective measures of physical functioning (PF) with education and material circumstances and the decline in PF with age by socioeconomic position (SEP). Methods: In 3,205 subjects (60-75 years) from the Czech Republic, we assessed relationship between PF, SEP, and age. Linear regression was used to assess PF measures and SEP measures. Results: Crosssectional decline in PF by age was similar in all individuals. Differences between SEP groups were similar across age groups, except for the difference in walk speed by material circumstances in men-bigger at older ages $(p=.004)$. Men and women with the highest education were about $2 \mathrm{~s}$ faster at the chair rise test than those with the lowest education. Discussion: Findings suggest strong educational gradient in PF, an inconsistent role of self-assessed material circumstances, and virtually no interaction of SEP with the cross-sectional decline in PF by age.
\end{abstract}

Keywords: chair rise, grip strength, walk speed, education, material circumstances, aging

There is good evidence that musculoskeletal fitness is related to health status; is a consistent predictor of mobility, disability, and independent living in the aging population (Katzmarzyk \& Craig, 2002); and that maintenance of muscle strength and physical functioning $(\mathrm{PF})$ throughout life reduces functional limitations and mortality (Berkman et al., 1993; Brill, Macera, Davis, Blair, \& Gordon, 2000; Camacho, Strawbridge, Cohen, \& Kaplan, 1993; Huang et al., 1998; Metter, Talbot, Schrager, \& Conwit, 2002). Higher levels of physical activity and aerobic fitness were reported to provide protective effects against physical age-related decline and premature mortality (Spirduso, Francis, \& MacRae, 2005). Muscle strength and PF have been confirmed (Rantanen et al., 2000) as powerful predictors of mortality for both chronic (Rantanen, Era, \& Heikkinen, 1997) and acute conditions (Rantanen, Era, Kauppinen, \& Heikkinen, 1994).

$\mathrm{PF}$, often measured in the aging population by grip strength, walk speed, and chair rise (Rantanen et al., 1994; Rantanen et al., 1997), is related to skeletal muscle mass, a significant site of glucose disposal and insulin action (Lazarus, Sparrow, \& Weiss, 1997). Low levels of PF play a role in higher mortality and morbidity from cardiovascular diseases and other conditions (Sasaki, Kasagi, Yamada, \& Fujita, 2007; Bittner et al., 1993; Milligan, Havey, \& Dossa, 1997; Steffen, Hacker, \& Mollinger, 2002; Kadikar, Maurer, \& Kesten, 1997).

Social conditions of the aging populations play an important role in their health and functioning. For example, retirement is associated with an increase in difficulties related to impaired mobility and daily activities, illnesses, and decline in mental health (Dave, Rashad, \& Spasojevic, 2006; Bassey, Fentem, MacDonald, Patrick, \& Scriven, 1977).

Jancova-Vseteckova is with the Faculty of Health and Social Care, The Open University, Milton Keynes, UK. Bobak, Peasey, Marmot, and Pikhart are with the Department of Epidemiology and Public Health, University College London, UK. Kubinova and Capkova are with the Centre for Environmental Health, National Institute of Public Health, Prague, Czech Republic. Address author correspondence to Jitka Jancova-Vseteckova at jitka.vseteckova@open.ac.uk.
Low education is often associated with higher incidence of poor health, chronic diseases, and disability (Avendano, Jürges, \& Mackenbach, 2009). Educational differentials in poor health vary across welfare states, presumably because different social contexts and economic policies shape the relationship between social position and health (Avendano et al., 2009; Espelt et al., 2008). Different societies can therefore exhibit different patterns of social inequalities. However, while there is ample evidence in Western countries, much less is known about the social gradient in aging-related outcomes in the former communist countries of Central and Eastern Europe. In addition, previous cross-sectional studies found that the age-related decline in PF was faster in Russia than in Western Europe (Andreev, McKee, \& Shkolnikov, 2003; Bobak, Kristenson, Pikhart, \& Marmot, 2004). Since Russia has worse health and more economic deprivation than Western Europe, the Russian-Western European comparisons may serve as an analogy to comparing higher and lower socioeconomic groups within a population, and it could be expected that, within populations, the age-related decline in $\mathrm{PF}$ is faster in those with low socioeconomic position (SEP) compared with those with high SEP.

In this paper, we examined the association of two markers of SEP (education and material circumstances) with three outcome measures of PF (grip strength, chair rise, and walk speed), and we analyzed the cross-sectional associations of PF measures with age by SEP.

\section{Methods}

\section{Participants}

The data come from the Czech-HAPIEE (Health and Psychosocial Factors in Eastern Europe) study, a part of an international collaborative project based in four European countries (Peasey et al., 2006). The Czech study examined a random population sample of men and women aged 45-69 years at baseline (2002-2005) in six towns (Havirov/Karvina, Hradec Kralove, Jihlava, Kromeriz, Liberec, and Usti nad Labem). For the purposes of this paper, only men and women aged 60 years and older were selected for analysis. 
The baseline data were collected through structured questionnaires and examination in clinic. The questionnaire covered health status, medical history, health behaviors and lifestyle, socioeconomic circumstances, and psychosocial factors. All questions were translated from English to Czech and then translated back to English for accuracy (Pikhart et al., 2009). The cohort was reexamined in 2006-2008 (i.e., about three years after the baseline). The reexamination included grip strength, chair rise, and walk speed testing. The response rate in the baseline survey was $55 \%$, and $70 \%$ of those who participated in the baseline survey attended the reexamination. For the present analyses, all data except for PF measures come from baseline survey, and individuals with missing data on covariates were excluded, leaving the following numbers of individuals in analysis: $N=2,927$ for walk speed; $N=2,944$ for chair rise, and $N=3,205$ for grip strength (Table 1).

\section{Materials and Procedures}

The following three measures of PF were used as outcome measures:

1. Grip strength. Grip strength was assessed twice for each hand, using a Smedley's hand dynamometer (Scandidact, Denmark). The maximum value (in kilograms) from two measurements on the dominant hand was selected for the analysis.

2. Chair rise. The ability to rise from a chair was measured by asking the subject to stand up from a chair five times without using their arms, and time was recorded.

3. Walk speed. The walk speed test recorded the time to walk a distance of $2.4 \mathrm{~m}$ at usual speed, and a walk speed (in $\mathrm{m} / \mathrm{s}$ ) was calculated as 2.4 divided by time recorded.

Education was classified into four categories: primary or less, vocational/apprenticeship, secondary, and university. Material circumstances were evaluated by three separate questions asking how often participants did not have enough money for food, for clothes, or for paying household bills. Each question had five possible answers: all the time, often, sometimes, rarely, or never. A sum of these three responses gave a score from 0 (no deprivation) to 12 (high deprivation). To make the effects of the two social measures (education and a measure of material circumstances) point in the same direction, we have inverted the score of material circumstances (so that 0 signifies "poor material circumstances" and 12 "good material circumstances"). Therefore, high scores of both education and material circumstances indicate more socially-advantaged individuals. For the analyses of functioning by age, binary measures of SEP were created, with those with less than secondary education being classified as "low education" and those without any financial difficulties (answering all three deprivation questions as "never") were classified as "good material circumstances".

\section{Data Analysis}

Statistical analyses were conducted in several steps. Firstly, cross tabulations were used showing distribution of the study outcomes; two main exposures and main covariates were tabulated separately for men and women.

Secondly, we fitted the mean values of the three outcome measures to each five-year age group in trends by binary measures of SEP using linear regression, and we tested for interactions between age groups and the SEP category.

Thirdly, the association between the study outcomes and exposures was assessed by linear regression. The full scale of the material circumstances score was used for construction of the Slope Index of Inequality (SII) as a composite measure of the magnitude of social inequalities. SII was originally developed by Pamuk (1985, 1988), and has been used extensively in recent years (Dorling, Shaw, \& Smith, 2006; Mackenbach \& Kunst, 1997; Mackenbach et al., 2008). Individual values of education and material circumstances were separately coded to be between 0 and 1, marking the relative position of an individual in the study population distribution of these two SEP variables ( 0 denotes that the individual is at the bottom of the distribution for the given variable and 1 denotes that the individual is at the top of the distribution). The main advantage of the index is that it takes into the account the size of each social group. This may be important because using such relative position

Table 1 Descriptive Data for Study Participants With Available Data on Grip Strength, Chair Rise, and Walk Speed

\begin{tabular}{|c|c|c|c|c|c|c|}
\hline & \multicolumn{2}{|c|}{ Hand Grip } & \multicolumn{2}{|c|}{ Chair Rise } & \multicolumn{2}{|c|}{ Walk Speed } \\
\hline & $\begin{array}{c}\text { Males } \\
\mathrm{N}=1,534\end{array}$ & $\begin{array}{c}\text { Females } \\
N=1,671\end{array}$ & $\begin{array}{c}\text { Males } \\
N=1,410\end{array}$ & $\begin{array}{c}\text { Females } \\
N=1,534\end{array}$ & $\begin{array}{c}\text { Males } \\
N=1,399\end{array}$ & $\begin{array}{c}\text { Females } \\
N=1,528\end{array}$ \\
\hline \multicolumn{7}{|l|}{ Age } \\
\hline Mean $(S D)$ & $67.1(4.0)$ & $67.0(3.9)$ & $67.1(4.0)$ & $66.9(3.9)$ & $67.2(3.9)$ & $67.0(3.9)$ \\
\hline $60-64$ & $33.4 \%$ & $34.7 \%$ & $33.7 \%$ & $35.3 \%$ & $32.8 \%$ & $34.6 \%$ \\
\hline $65-69$ & $37.8 \%$ & $38.3 \%$ & $37.8 \%$ & $38.1 \%$ & $38.3 \%$ & $38.2 \%$ \\
\hline $70+$ & $28.8 \%$ & $27.1 \%$ & $28.5 \%$ & $26.6 \%$ & $28.9 \%$ & $28.2 \%$ \\
\hline \multicolumn{7}{|l|}{ Education } \\
\hline Primary or less & $5.3 \%$ & $18.8 \%$ & $5.2 \%$ & $17.6 \%$ & $5.2 \%$ & $17.9 \%$ \\
\hline Vocational & $39.6 \%$ & $30.4 \%$ & $38.9 \%$ & $30.1 \%$ & $39.6 \%$ & $30.2 \%$ \\
\hline Secondary & $34.8 \%$ & $40.3 \%$ & $35.2 \%$ & $41.2 \%$ & $34.9 \%$ & $41.3 \%$ \\
\hline University & $20.4 \%$ & $10.5 \%$ & $20.7 \%$ & $11.1 \%$ & $20.3 \%$ & $10.5 \%$ \\
\hline \multicolumn{7}{|c|}{ Material circumstances } \\
\hline Good & $93.6 \%$ & $87.5 \%$ & $94.0 \%$ & $87.7 \%$ & $93.3 \%$ & $86.7 \%$ \\
\hline Poor & $6.4 \%$ & $12.5 \%$ & $6.0 \%$ & $12.3 \%$ & $6.7 \%$ & $13.3 \%$ \\
\hline
\end{tabular}


in the population instead of the original coding makes the effects of several measures of SEP directly comparable. SII indicates the absolute difference in the outcome between individuals at the bottom and at the top of the scale.

Three models were used to estimate SII. Firstly, the effect of material circumstances or education on the study outcomes was only adjusted for age, sex, and town of residence. Secondly, the relationship was additionally adjusted for marital status, self-rated health (as a proxy measure of objective health conditions), height, and weight. Finally, the effects of education and material circumstances were mutually adjusted by including both variables into same model.

\section{Ethics}

The study received ethical approval from the University College London/University College London Hospital (UK) joint research ethics committee and from the ethical committee at National Institute of Public Health, Prague (CR). All participants gave written informed consent.

\section{Results}

Table 1 shows descriptive characteristics of the study sample. The mean age at reexamination was 67.1 years for males and 67.0 years for females (using the largest number of participants with valid data on hand grip).

As expected, all three PF measures declined with age group (Table 2) and in all socioeconomic groups (Figure 1). For example, subjects aged 60-64 years were, on average, more than $1 \mathrm{~s}$ faster than those aged $70+$ in the chair rise test in all socioeconomic groups. For all PF tests, subjects with higher SEP performed better than those with low SEP, except for walk speed and material circumstances in women. In most comparisons, differences between high and low SEP group were similar across the age range; in the few instances where the slopes with age were not parallel, the interaction of SEP with age was not statistically significant (all $p$ values were larger than .20) except for the case of walk speed and material circumstances in men ( $p$ for interaction of SEP with age was .004).

The SII by education and material circumstances are shown in Table 3. After controlling for age and town, all PF outcomes were statistically significantly associated with education, while only grip strength in women and walk speed in men were significantly associated with material circumstances. The association of grip strength with both SEP variables were substantially reduced after further adjustment for marital status, self-rated health, height, and weight; with the effect of education being considerably attenuated. The mutual adjustment for education and material circumstances had almost no effect on the reported associations.

The associations between education and chair rise and walk speed, respectively, remained significant in all models in both men and women, suggesting that more educated participants achieved better results. The association between material circumstances and chair rise was not significant, and only marginally significant in multivariate model for walk speed in men; there was no statistically significant relationship in women after controlling for covariates.

The magnitude of the educational differences was not trivial; for chair rise, men and women at the top of educational ladder were more than $1.8 \mathrm{~s}$ and $2 \mathrm{~s}$, respectively, faster than those at the bottom of the educational ladder. This difference is equivalent to approximately half of standard deviation. For walk speed test, the difference between those at the top and the bottom of educational range is approximately $0.10 \mathrm{~m} / \mathrm{s}$. As the mean chair rise was approximately $10 \mathrm{~s}$, and mean walk speed was approximately $0.9 \mathrm{~m} / \mathrm{s}$, the SII found in our study is substantial (equivalent to $10-20 \%$ of mean values).

\section{Discussion}

This study, in a general population sample in a Central European country, is one of the first and probably the largest evaluation of objectively measured physical functions in this region. We found a strong educational gradient in two objective measures of PF (chair rise and walk speed), but not in grip strength. There were no clear and significant gradients in any of the functioning measures by material circumstances. The gradient of the cross-sectional decline in function with age was similar in high and low socioeconomic categories.

\section{Limitations of the Study}

There are several limitations in our study that should be considered when interpreting the results. First, approximately $70 \%$ of baseline participants attended reexamination. It is likely that those participants in reexamination had better health than nonresponders, and our results probably overestimate the population level of functioning, particularly in participants aged 70 and older. In addition, the response rate for the baseline survey was only $55 \%$, which further increases the possibility that our results are overoptimistic in relation to the levels of functioning in the Czech population, and if the

Table 2 Mean (SD) Grip Strength, Chair Rise, and Walk Speed by Age and Sex

\begin{tabular}{|c|c|c|c|c|c|c|}
\hline & \multicolumn{2}{|c|}{ Hand Grip } & \multicolumn{2}{|c|}{ Chair Rise } & \multicolumn{2}{|c|}{ Walk Speed } \\
\hline & $\begin{array}{c}\text { Males } \\
N=1,534\end{array}$ & $\begin{array}{c}\text { Females } \\
N=1,671\end{array}$ & $\begin{array}{c}\text { Males } \\
N=1,410\end{array}$ & $\begin{array}{c}\text { Females } \\
N=1,534\end{array}$ & $\begin{array}{c}\text { Males } \\
N=1,399\end{array}$ & $\begin{array}{c}\text { Females } \\
N=1,528\end{array}$ \\
\hline \multicolumn{7}{|c|}{ Age group } \\
\hline $60-64$ & 46.7 (7.2) & $29.0(5.1)$ & $9.3(3.4)$ & $10.6(3.4)$ & $2.9(0.8)$ & $3.0(1.0)$ \\
\hline $65-69$ & $44.1(7.6)$ & $27.6(4.9)$ & $10.2(4.8)$ & $11.2(3.6)$ & $3.0(0.9)$ & $3.3(1.1)$ \\
\hline $70+$ & $41.9(7.0)$ & $25.8(5.0)$ & $10.5(4.4)$ & $13.0(4.7)$ & $3.2(1.1)$ & $3.6(1.2)$ \\
\hline
\end{tabular}



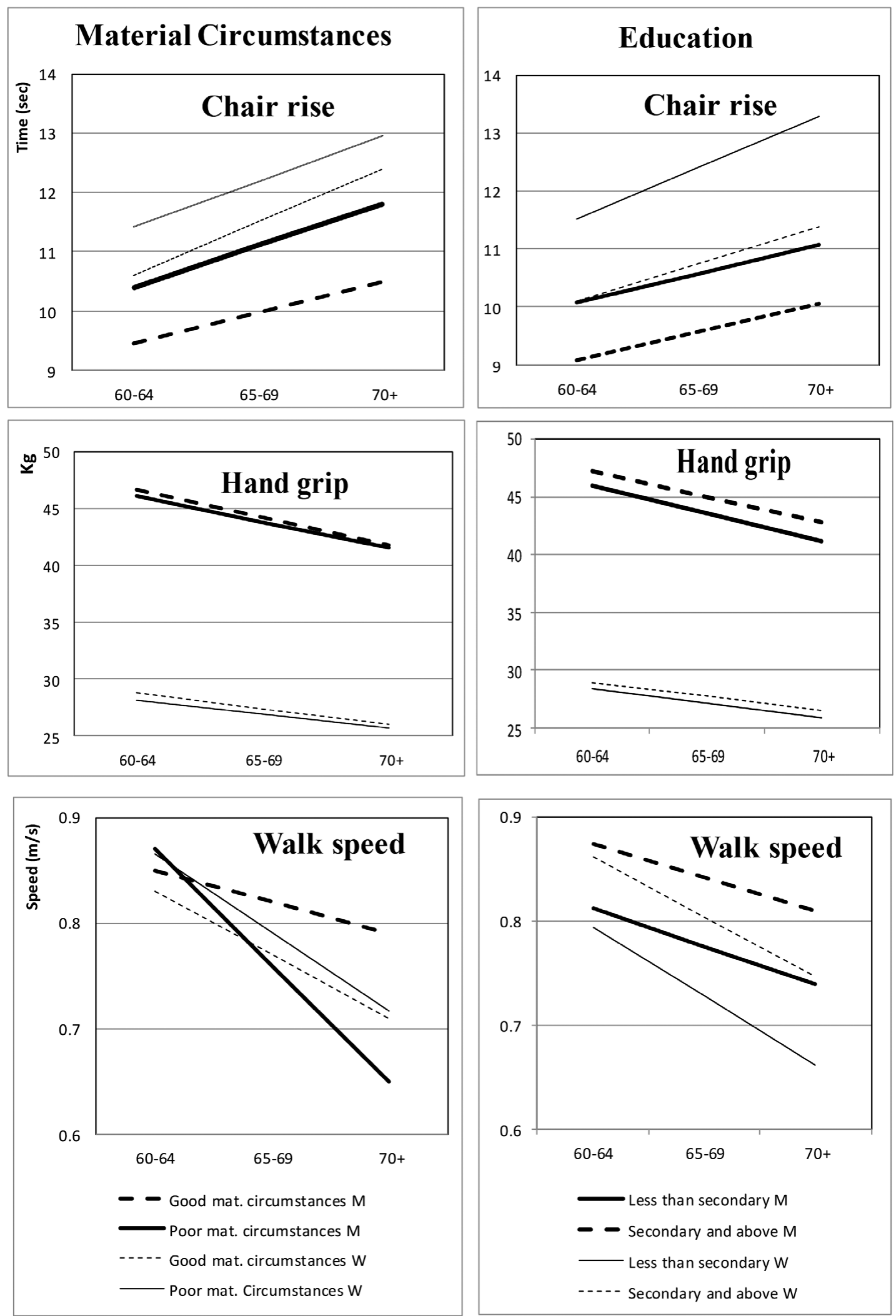

Figure 1 - Mean levels of chair rise, hand grip, and walk speed by levels of material circumstances and education in men (M) and women (W). 


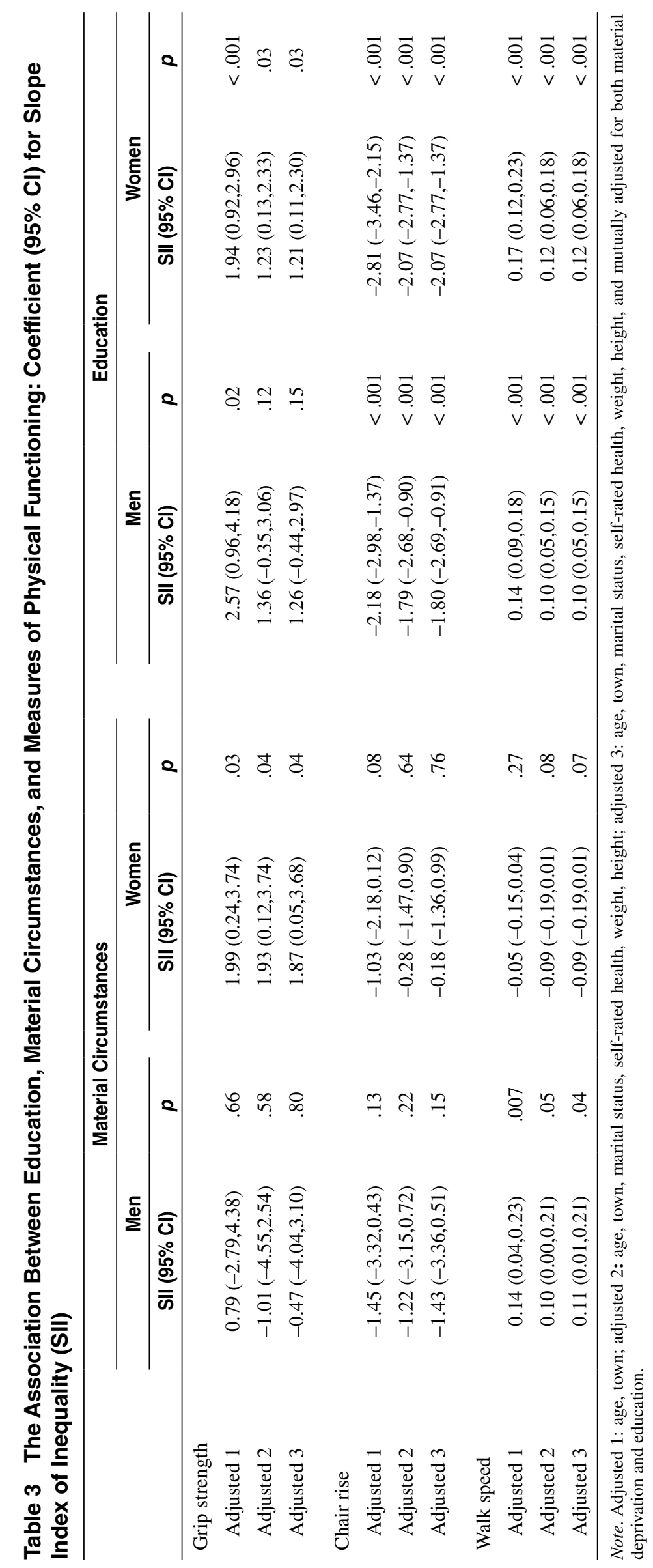


selection bias is more pronounced among older persons (healthy survivors), the slope of the cross-sectional decline in PF with age may be underestimated. On the other hand, it is unlikely that this selection bias would materially affect the estimates of the social gradient in functioning. That would require a complex selection bias mechanism associated with various combinations of PF levels and SEP group. While this is not impossible, we believe that this is unlikely.

Second, our study included only urban populations, and while we do not expect substantial differences between urban and rural population in muscle strength, we cannot directly extrapolate our results to be representative for the whole country.

Third, the measure of material circumstances was based on subjective responses and it is possible that it is less reliable than objective measures, such as income. Unfortunately, income was not asked in the baseline survey. On the other hand, the classification of education is likely to be more reliable than material circumstances since these are formal educational categories that are well understood by the population, and also because education is fixed at a relatively early age. The suspected lower reliability of the material circumstances measure, compared with education, may lead to underestimation of its association with $\mathrm{PF}$ and thus make material circumstances appear less important for health than education.

Finally, the cross-sectional design does not allow detailed assessment of temporality. For example, we were unable to trace individual subjects' decline in PF over time; the association in our study is cross-sectional, comparing different birth cohorts, and the association with age may not be identical to that observed in longitudinal data. Similarly, the temporality of the association with material circumstances is also unclear; at least to some extent, poor PF may lead to worsening of material circumstances, for example through reduced ability to do paid work in addition to receiving a pension.

\section{Interpretation of the Findings}

We hypothesized that the age-related decline in physical function would be faster in those with low SEP compared with those with higher SEP. The overall finding of a significant decline in functioning with age is in line with previous studies (Brill et al., 2000; Brooks \& Faulkner, 1994; Delmonico et al., 2009; Frontera, Hughes, Lutz, \& Evans, 1991; Frontera et al., 2000; Goodpaster et al., 2006; Katzmarzyk \& Craig, 2002; Lindle et al., 1997; Spirduso et al., 2005). However, we did not confirm the hypothesis that the decline in PF with age is steeper in low SEP compared with high SEP groups. Most tests of interactions between SEP and age were nonsignificant. However, there was a suggestion in our data that more deprived men performed better in the walk speed test when aged 60-64, but their walk speed worsened steeply so that at age $70+$ their performance was far worse than in less deprived subjects. We could speculate that men in less privileged positions may have worked in more physically-demanding occupations and, as a consequence, were more physically fit before retirement compared with those in more privileged positions (mostly working in sedentary jobs). However, once retired and having stopped working physically, the changes in their lifestyle was probably larger and with greater impact, and their physical decline was, as a consequence, faster than those whose lifestyle did not change that much.

We have found a clear educational gradient in walk speed and chair rise. We have not, however, found a social gradient in grip strength after controlling for covariates. Our findings are generally in agreement with many previous studies showing that educational level plays an important role in PF, mobility, disability, and cognitive decline in aging populations (Callahan \& Pincus, 1988; Coppin, Ferrucci, et al., 2006; Coppin, Shumway-Cook, et al., 2006; Patel et al., 2006; Groffen, Bosma, Van Den Akker, Kempen, \& Van Eijk, 2008; Rantanen, Parkatti, \& Heikkinen, 1992). The similarity of results on chair rise and walk speed, and their correlation, is also not surprising as both tests measure lower limb muscle strength (Steffen et al., 2002). However, we are not certain why grip strength did not show a similar educational gradient. More authors also reported that in older individuals, upper limb function is better preserved that lower limb function with some differences between the sexes (Candow \& Chilibeck, 2005; Macaluso \& DeVito, 2004). It has been previously reported that men exhibit a steeper age-related decline in muscle function than women (Ditroilo, Forte, Benelli, Gambarara, \& De Vito, 2010); the same authors also reported a slower rate of decline and smaller difference between hand grip and lower limb strength in women. This was attributed to the dissemblance in muscle mass between the regions of the body in the two sexes and in the age-related changes (Ditroilo et al., 2010). Alternatively, we can speculate that most people in this urban population continue manual activities (cooking, knitting, or light gardening) that maintain hand and arm strength, and this may explain why hand and leg strengths decline at different speeds in this study.

Our results showing a stronger gradient by education than by material circumstances would suggest that direct material effects are not as important as indirect effects influenced by different levels of education. This is consistent with findings from another study of various health outcomes, suggesting that education is probably the best social predictor of health inequalities in postcommunist countries in middle-aged or older populations (Bobák, Hertzman, Škodová, \& Marmot, 2000).

There are several possible explanations for the different effects of education and material circumstances. First, as discussed among the limitations above, one possible explanation for the inconsistent effect of material circumstances is a measurement problem. In other words, the index used in our analysis may not be a reliable measure of material conditions. In fact, education, a good predictor of PF in our data, may be a proxy for and partly operate through material pathways. It is likely that better material circumstances allow better access to health care, a higher chance to participate in sports and recreational activities, and better access to good quality food. Poor performance in PF tests can be, at least partly, attributed to a poorer diet. This would agree with previous reports describing the effect of malnutrition on muscles weakness and morbidity in aging populations (Fiatarone et al., 1994; Norman et al., 2005).

Second, some authors have suggested that better education means better access to information, better critical thinking skills, and better decision-making abilities compared with less educated individuals (Cutler \& Lleras-Muney, 2006; Kenkel, 1991; Marmot, 2002). More educated individuals may be able to make better and healthier choices. This may also help explain why more educated individuals have generally better results in all PF tests.

Third, education reflects SEP at a relatively early stage of life (Chittleborough, Baum, Taylor, \& Hiller, 2006), and may therefore serve as a proxy to life course accumulation of social disadvantage and associated risky characteristics (e.g., smoking, alcohol consumption, and diet).

Finally, it is also possible that social differences in material conditions in older individuals in this population at the time of the study were not sufficiently large to give rise to a measurable impact on functional outcomes. In fact, only a very small proportion of individuals reported having financial difficulties that would result in material deprivation and a low score for material 
circumstances in our analysis. International data suggest that in the Czech Republic the rise of income inequality and decline in income during the societal transition following the fall of communism were relatively small, compared with other postcommunist countries (UNICEF, 2003). However, there are insufficient individual level data to support this optimistic view, and better quality data on material circumstances such as income, family transfers, and, in particular, wealth (McMunn, Nazroo, \& Breeze, 2009) would be needed to address the association between material circumstances and PF.

\section{Conclusions}

This study in a general population sample, the largest to date in Central and Eastern Europe, found a strong association in objective measures of $\mathrm{PF}$ with education but a weak and inconsistent relationship with material circumstances. While some of the weak effects of material circumstances may be due to measurement issues, it is also possible that education is a better and more long-term marker of SEP in postcommunist countries to assess health inequalities.

\section{Acknowledgments}

This work was supported by a grant from the Wellcome Trust "Determinants of Cardiovascular Diseases in Eastern Europe: A multi-centre cohort study" (Reference number 064947/Z/01/Z) and "Determinants of Cardiovascular Diseases in Eastern Europe: Longitudinal follow-up of a multi-centre cohort study (The HAPIEE Project)" (Reference number 081081/Z/06/Z); a grant from the National Institute on Aging "Health disparities and aging in societies in transition (the HAPIEE study)", grant number 1R01 AG23522-01; and a grant from MacArthur Foundation "Health and Social Upheaval (a research network)". We would like to thank researchers, interviewers, and participants in Havířov/Karviná, Jihlava, Ústí nad Labem, Liberec, Hradec Králové, and Kroměříz.

\section{References}

Andreev, E.M., McKee, M., \& Shkolnikov, V.M. (2003). Health expectancy in the Russian federation: A new perspective on the health divide in europe. Bulletin of the World Health Organization, 81(11), 778-787. PubMed

Avendano, M., Jürges, H., \& Mackenbach, J.P. (2009). Educational level and changes in health across Europe: Longitudinal results from SHARE. Journal of European Social Policy, 19(4), 301-316. doi:10.1177/1350506809341512

Bassey, E.J., Fentem, P., MacDonald, I., Patrick, J., \& Scriven, P.M. (1977). A study of exercise performance and heart rate: The response to exercise of a small group of manual workers before and after retirement. Age and Ageing, 6(4), 232-237. PubMed doi:10.1093/ageing/6.4.232

Berkman, L.F., Seeman, T.E., Albert, M., Blazer, D., Kahn, R., Mohs, R., \& McClearn, G. (1993). High, usual and impaired functioning in community-dwelling older men and women: Findings from the MacArthur foundation research network on successful aging. Journal of Clinical Epidemiology, 46(10), 1129-1140. PubMed doi:10.1016/0895-4356(93)90112-E

Bittner, V., Weiner, D.H., Yusuf, S., Rogers, W.J., McIntyre, K.M., Bangdiwala, S.I., \& Guillotte, M. (1993). Prediction of mortality and morbidity with a 6-minute walk test in patients with left ventricular dysfunction. Journal of the American Medical Association, 270(14), 1702-1707. PubMed doi:10.1001/jama.1993.03510140062030

Bobák, M., Hertzman, C., Škodová, Z., \& Marmot, M. (2000). Own education, current conditions, parental material circumstances, and risk of myocardial infarction in a former communist country. Journal of Epidemiology and Community Health, 54(2), 91-96. PubMed doi:10.1136/jech.54.2.91

Bobak, M., Kristenson, M., Pikhart, H., \& Marmot, M. (2004). Life span and disability: A cross sectional comparison of Russian and Swedish community based data. BMJ (Clinical Research Ed.), 329(7469), 767. PubMed doi:10.1136/bmj.38202.667130.55

Brill, P.A., Macera, C.A., Davis, D.R., Blair, S.N., \& Gordon, N. (2000). Muscular strength and physical function. Medicine and Science in Sports and Exercise, 32(2), 412-416. PubMed doi:10.1097/00005768200002000-00023

Brooks, S.V., \& Faulkner, J.A. (1994). Skeletal muscle weakness in old age: Underlying mechanisms. Medicine and Science in Sports and Exercise, 26(4), 412-416. PubMed doi:10.1249/00005768-199404000-00006

Callahan, L.F., \& Pincus, T. (1988). Formal education level as a significant marker of clinical status in rheumatoid arthritis. Arthritis and Rheumatism, 31(11), 1346-1357. PubMed doi:10.1002/art.1780311102

Camacho, T.C., Strawbridge, W.J., Cohen, R.D., \& Kaplan, G.A. (1993). Functional ability in the oldest old. Journal of Aging and Health, 5(4), 439-454. doi:10.1177/089826439300500402

Candow, D.G., \& Chilibeck, P.D. (2005). Differences in size, strength, and power of upper and lower body muscle groups in young and older men. The Journals of Gerontology. Series A, Biological Sciences and Medical Sciences, 60, 148-156. PubMed doi:10.1093/gerona/60.2.148

Chittleborough, C.R., Baum, F.E., Taylor, A.W., \& Hiller, J. (2006). A lifecourse approach to measuring socioeconomic position in population health surveillance systems. Journal of Epidemiology and Community Health, 60(11), 981-992. PubMed doi:10.1136/jech.2006.048694

Coppin, A.K., Ferrucci, L., Lauretani, F., Phillips, C., Chang, M., Bandinelli, S., \& Guralnik, J.M. (2006). Low socioeconomic status and disability in old age: Evidence from the InChianti study for the mediating role of physiological impairments. The Journals of Gerontology. Series A, Biological Sciences and Medical Sciences, 61(1), 86-91. PubMed doi:10.1093/gerona/61.1.86

Coppin, A.K., Shumway-Cook, A., Saczynski, J.S., Patel, K.V., Ble, A., Ferrucci, L., \& Guralnik, J.M. (2006). Association of executive function and performance of dual-task physical tests among older adults: Analyses from the InChianti study. Age and Ageing, 35(6), 619-624. PubMed doi:10.1093/ageing/afl107

Cutler, D.M., \& Lleras-Muney, A. (2006). Education and Health: Evaluating Theories and Evidence. National Bureau of Economic Research.

Dave, D., Rashad, I., \& Spasojevic, J. (2006). The Effects of Retirement on Physical and Mental Health Outcomes. National Bureau of Economic Research.

Delmonico, M.J., Harris, T.B., Visser, M., Park, S.W., Conroy, M.B., Velasquez-Mieyer, P., \& Newman, A.B. (2009). Longitudinal study of muscle strength, quality, and adipose tissue infiltration. The American Journal of Clinical Nutrition, 90(6), 1579-1585. PubMed doi:10.3945/ ajen.2009.28047

Ditroilo, M., Forte, R., Benelli, P., Gambarara, D., \& De Vito, G. (2010). Effects of age and limb dominance on upper and lower limb muscle function in healthy males and females aged 40-80 years. Journal of Sports Sciences, 28(6), 667-677. PubMed doi:10.1080/02640411003642098

Dorling, D., Shaw, M., \& Smith, G.D. (2006). HIV and global health: Global inequality of life expectancy due to AIDS. BMJ: British Medical Journal, 332(7542), 662. doi:10.1136/bmj.332.7542.662

Espelt, A., Borrell, C., Rodríguez-Sanz, M., Muntaner, C., Pasarín, M.I., Benach, J., \& Navarro, V. (2008). Inequalities in health by social class dimensions in European countries of different political traditions. International Journal of Epidemiology, 37(5), 1095-1105. PubMed doi:10.1093/ije/dyn051

Fiatarone, M.A., O’Neill, E.F., Ryan, N.D., Clements, K.M., Solares, G.R., Nelson, M.E., \& Evans, W.J. (1994). Exercise training and nutritional supplementation for physical frailty in very elderly people. The New England Journal of Medicine, 330(25), 1769-1775. PubMed doi:10.1056/NEJM199406233302501

Frontera, W.R., Hughes, V.A., Fielding, R.A., Fiatarone, M.A., Evans, W.J., \& Roubenoff, R. (2000). Aging of skeletal muscle: A 12-yr 
longitudinal study. Journal of Applied Physiology, 88(4), 1321-1326. PubMed

Frontera, W.R., Hughes, V.A., Lutz, K.J., \& Evans, W.J. (1991). A crosssectional study of muscle strength and mass in 45-to 78-yr-old men and women. Journal of Applied Physiology, 71(2), 644-650. PubMed

Goodpaster, B.H., Park, S.W., Harris, T.B., Kritchevsky, S.B., Nevitt, M., Schwartz, A.V., \& Newman, A.B. (2006). The loss of skeletal muscle strength, mass, and quality in older adults: The health, aging and body composition study. The Journals of Gerontology. Series A, Biological Sciences and Medical Sciences, 61(10), 1059-1064. PubMed doi:10.1093/gerona/61.10.1059

Groffen, D.A.I., Bosma, H., Van Den Akker, M., Kempen, G.I.J.M., \& Van Eijk, J.T.M. (2008). Material deprivation and health-related dysfunction in older dutch people: Findings from the SMILE study. European Journal of Public Health, 18(3), 258-263. PubMed doi:10.1093/ eurpub/ckm119

Huang, Y., Macera, C.A., Blair, S.N., Brill, P.A., Kohl, H.W., \& Kronefeld, J.J. (1998). Physical fitness, physical activity, and functional limitation in adults aged 40 and older. Medicine and Science in Sports and Exercise, 30(9), 1430-1435. PubMed

Kadikar, A., Maurer, J., \& Kesten, S. (1997). The six-minute walk test: A guide to assessment for lung transplantation. The Journal of Heart and Lung Transplantation: The Official Publication of the International Society for Heart Transplantation, 16(3), 313-319. PubMed

Katzmarzyk, P.T., \& Craig, C.L. (2002). Musculoskeletal fitness and risk of mortality. Medicine and Science in Sports and Exercise, 34(5), 740-744. PubMed doi:10.1097/00005768-200205000-00002

Kenkel, D.S. (1991). Health behavior, health knowledge, and schooling. Journal of Political Economy, 99(2), 287-305. doi:10.1086/261751

Lazarus, R., Sparrow, D., \& Weiss, S.T. (1997). Handgrip strength and insulin levels: Cross-sectional and prospective associations in the normative aging study. Metabolism: Clinical and Experimental, 46(11), 1266-1269. PubMed doi:10.1016/S0026-0495(97)90228-6

Lindle, R.S, Metter, E., Lynch, N., Fleg, J., Fozard, J., Tobin, J., \& Hurley, B. (1997). Age and gender comparisons of muscle strength in 654 women and men aged 20-93 yr. Journal of Applied Physiology, 83(5), 1581-1587. PubMed

Macaluso, A., \& De Vito, G. (2004). Muscle strength, power and adaptations to resistance training in older people. European Journal of Applied Physiology, 91, 450-472. PubMed doi:10.1007/s00421-003-0991-3

Mackenbach, J.P., \& Kunst, A.E. (1997). Measuring the magnitude of socioeconomic inequalities in health: An overview of available measures illustrated with two examples from europe. Social Science \& Medicine, 44(6), 757-771. PubMed doi:10.1016/S0277-9536(96)00073-1

Mackenbach, J.P., Stirbu, I., Roskam, A.J.R., Schaap, M.M., Menvielle, G., Leinsalu, M., \& Kunst, A.E. (2008). Socioeconomic inequalities in health in 22 european countries. The New England Journal of Medicine, 358(23), 2468-2481. PubMed doi:10.1056/NEJMsa0707519

Marmot, M. (2002). The influence of income on health: Views of an epidemiologist. Health Affairs, 21(2), 31-46. PubMed doi:10.1377/ hlthaff.21.2.31

McMunn, A., Nazroo, J., \& Breeze, E. (2009). Inequalities in health at older ages: a longitudinal investigation of the onset of illness and survival effects in England. Age and Ageing, 38(2), 181-187. PubMed doi:10.1093/ageing/afn236

Metter, E.J., Talbot, L.A., Schrager, M., \& Conwit, R. (2002). Skeletal muscle strength as a predictor of all-cause mortality in healthy men. The Journals of Gerontology. Series A, Biological Sciences and Medical Sciences, 57(10), B359-B365. PubMed doi:10.1093/gerona/57.10.B359
Milligan, N.P., Havey, J., \& Dossa, A. (1997). Using a 6-minute walk test to predict outcomes in patients with left ventricular dysfunction. Rehabilitation Nursing: The Official Journal of the Association of Rehabilitation Nurses, 22(4), 177-181. PubMed doi:10.1002/j.2048-7940.1997. tb02095.x

Norman, K., Schütz, T., Kemps, M., Josef Lübke, H., Lochs, H., \& Pirlich, M. (2005). The subjective global assessment reliably identifies malnutrition-related muscle dysfunction. Clinical Nutrition (Edinburgh, Scotland), 24(1), 143-150. PubMed doi:10.1016/j.clnu.2004.08.007

Pamuk, E.R. (1985). Social class inequality in mortality from 1921 to 1972 in England and Wales. Population Studies, 39(1), 17-31. PubMed doi:10.1080/0032472031000141256

Pamuk, E.R. (1988). Social-class inequality in infant mortality in England and Wales from 1921 to 1980. European Journal of Population/Revue Européenne De Démographie, 4(1), 1-21.

Patel, K.V., Coppin, A.K., Manini, T.M., Lauretani, F., Bandinelli, S., Ferrucci, L., \& Guralnik, J.M. (2006). Midlife physical activity and mobility in older age: The InCHIANTI study. American Journal of Preventive Medicine, 31(3), 217-224. PubMed doi:10.1016/j. amepre.2006.05.005

Peasey, A., Bobak, M., Kubinova, R., Malyutina, S., Pajak, A., Tamosiunas, A., \& Marmot, M. (2006). Determinants of cardiovascular disease and other non-communicable diseases in central and eastern Europe: Rationale and design of the HAPIEE study. BMC Public Health, 6(1), 255. PubMed doi:10.1186/1471-2458-6-255

Pikhart, H., Hubacek, J.A., Kubinova, R., Nicholson, A., Peasey, A., Capkova, N., \& Bobak, M. (2009). Depressive symptoms and levels of C-reactive protein. Social Psychiatry and Psychiatric Epidemiology, 44(3), 217-222. PubMed doi:10.1007/s00127-008-0422-1

Rantanen, T., Era, P., \& Heikkinen, E. (1997). Physical activity and the changes in maximal isometric strength in men and women from the age of 75 to 80 years. Journal of the American Geriatrics Society, 45(12), 1439-1445. PubMed

Rantanen, T., Era, P., Kauppinen, M., \& Heikkinen, E. (1994). Maximal isometric muscle strength and socio-economic status, health and physical activity in 75-year-old persons. Journal of Aging and Physical Activity, 2, 206-220.

Rantanen, T., Harris, T., Leveille, S.G., Visser, M., Foley, D., Masaki, K., \& Guralnik, J.M. (2000). Muscle strength and body mass index as long-term predictors of mortality in initially healthy men. The Journals of Gerontology. Series A, Biological Sciences and Medical Sciences, 55(3), M168-M173. PubMed doi:10.1093/gerona/55.3.M168

Rantanen, T., Parkatti, T., \& Heikkinen, E. (1992). Muscle strength according to level of physical exercise and educational background in middle-aged women in finland. European Journal of Applied Physiology and Occupational Physiology, 65(6), 507-512. PubMed doi:10.1007/BF00602356

Sasaki, H., Kasagi, F., Yamada, M., \& Fujita, S. (2007). Grip strength predicts cause-specific mortality in middle-aged and elderly persons. The American Journal of Medicine, 120(4), 337-342. PubMed doi:10.1016/j.amjmed.2006.04.018

Spirduso, W.W., Francis, K.L., \& MacRae, P.G. (2005). Physical dimensions of aging. Champaign, IL: Human Kinetics Publishers.

Steffen, T.M., Hacker, T.A., \& Mollinger, L. (2002). Age-and gender-related test performance in community-dwelling elderly people: Six-minute walk test, berg balance scale, timed up \& go test, and gait speeds. Physical Therapy, 82(2), 128-137. PubMed

UNICEF. (2003). Social monitor 2003: Social trends in transition. Florence: UNICEF Innocenti Research Centre. 